\title{
BMJ Open Patient and provider factors associated with enrolment in the pre-end-stage renal disease pay-for-performance programme in Taiwan: a cross- sectional study
}

Hsiao-Yun Hu, ${ }^{1}$ Feng-Xuan Jian, ${ }^{2}$ Yun-ju Lai, ${ }^{\circledR}{ }^{3}$ Yung-Feng Yen, ${ }^{4}$ Nicole Huang, ${ }^{5}$ Shang Jyh Hwang ${ }^{6}$

To cite: Hu H-Y, Jian F-X, Lai $Y$, et al. Patient and provider factors associated with enrolment in the preend-stage renal disease pay-for-performance programme in Taiwan: a crosssectional study. BMJ Open 2019;9:e031354. doi:10.1136/ bmjopen-2019-031354

\section{- Prepublication history for} this paper is available online. To view these files, please visit the journal online (http://dx.doi org/10.1136/bmjopen-2019031354).

Received 29 April 2019 Revised 24 August 2019 Accepted 28 August 2019
Check for updates

(C) Author(s) (or their employer(s)) 2019. Re-use permitted under CC BY-NC. No commercial re-use. See rights and permissions. Published by BMJ.

For numbered affiliations see end of article.

Correspondence to Dr Nicole Huang; syhuang@ms.ym.edu.tw

\section{ABSTRACT}

Objective The incidence and prevalence of end-stage renal disease (ESRD) in Taiwan have been ranked the highest worldwide. Therefore, the National Health Insurance Administration has implemented the pre-ESRD pay-for-performance (P4P) programme since November 2006, which had significantly reduced the incidence of dialysis and all-cause mortality. This study aimed to identify the factors associated with the enrolment in the pre-ESRD P4P programme.

Design Cross-sectional study.

Setting The National Health Insurance research database 2007-2012 in Taiwan.

Participants Patients with prevalent pre-ESRD aged more than 18 years between January 2007 and December 2012 were enrolled. Patient demographics and hospital characteristics between P4P and non-P4P groups were compared. A logistic regression model was used to analyse the factors associated with P4P enrolment, and a generalised estimating equation was used to verify the results.

Primary outcome measure Enrolment in the pre-ESRD P4P programme.

Results In total, 82991 patients were enrolled in the programme, with a $45.6 \%$ participation rate. Patients who were males (adjusted OR $(\mathrm{AOR})=0.89,95 \% \mathrm{Cl}=0.86$ to 0.91) and employed ( $\mathrm{AOR}=0.95,95 \% \mathrm{Cl}=0.92$ to 0.97 ) had a significantly lower probability to be enrolled in the programme. Older patients (66-75 years old, $\mathrm{AOR}=1.23$, $95 \% \mathrm{Cl}=1.14$ to 1.33 ) and those with higher Charlson Comorbidities Index (CCl 5+, A0R=4.01, 95\% Cl=3.55 to 4.53 ) tended to be enrolled in the programme, while those in the 76+ years age group were not $(\mathrm{AOR}=1.03$, $95 \% \mathrm{Cl}=0.95$ to 1.13). Hospitals located in the central ( $\mathrm{AOR}=1.48,95 \% \mathrm{Cl}=1.05$ to 2.08 ) and Kao-Ping regions ( $A O R=1.62,95 \% \mathrm{Cl}=1.18$ to 2.22 ) also tended to enrol patients in the pre-ESRD P4P programme. Enrolment rates increased over time.

Conclusion Pre-ESRD patients of the female gender, greater age and more comorbidities were more likely to be enrolled in the pre-ESRD P4P programme. Healthcare providers and health authorities should focus attention on patients who are male, younger and with less
Strengths and limitations of this study

- We used the nationwide health insurance data which is representative for the whole Taiwan population.

- Both detailed patient and provider factors were analysed, and a generalised estimating equation was used to verify the results.

- This was a cross-sectional study, in which it is difficult to investigate causal relationships.

- Laboratory data were not available in the health insurance data set.

- The national health insurance system and the preend-stage renal disease pay-for-performance programme are unique in Taiwan, and the results may not apply to other countries in the world.

comorbidities to improve the healthcare quality and equality for all pre-ESRD patients.

\section{INTRODUCTION}

Chronic kidney disease (CKD) is a wellknown risk factor for cardiovascular disease, ${ }^{1}$ which increases morbidities and mortalities and causes large-scale health expenditure worldwide. The global prevalence of CKD was estimated to be ranging from $11 \%$ to $13 \%$, and the prevalence of CKD stages 3-5 was $10.6 \% .^{2}$ Taiwan has the highest prevalence of end-stage renal disease (ESRD) in the world, ${ }^{3}$ and the costs of dialysis constitute $8 \%$ of the total medical expenditure. ${ }^{4}$ In many countries, including the UK, the USA, Australia, Canada and Japan, a pay-for-performance (P4P) programme has been introduced for the care of the CKD or dialysis population..$^{5-9}$

The pre-ESRD P4P programme in Taiwan had significantly reduced the incidence of dialysis and all-cause mortality. The time to dialysis treatment is significantly longer in patients enrolled in the $\mathrm{P} 4 \mathrm{P}$ programme, 
compared with those who didn't receive healthcare from the $\mathrm{P} 4 \mathrm{P}$ programme. ${ }^{4}$ In addition, even when kidney function deteriorated and the patient required long-term dialysis, the 4-year total healthcare expenditures of patients enrolled in the $\mathrm{P} 4 \mathrm{P}$ programme continued to show a $68 \%$ reduction compared with those without healthcare from the $\mathrm{P} 4 \mathrm{P}$ programme. The mortality within 3 years of dialysis of the patients with $\mathrm{P} 4 \mathrm{P}$ programme care was also significantly lower than those without $\mathrm{P} 4 \mathrm{P}$ programme care. $^{10}$

Although pre-ESRD P4P programme could significantly improve the outcome in patients with CKD, it was estimated that the participation rate in the $\mathrm{P} 4 \mathrm{P}$ programme is less than $50 \% .{ }^{6}$ The participation rate in pre-ESRD programme before dialysis has increased year by year, from $25.1 \%$ in 2010 to $36.7 \%$ in $2014 .^{11}$ Many patients with advanced stages of CKD may not receive sufficient healthcare, ${ }^{12}$ which could lead to poor disease prognosis, life quality and additional health expenditure. The relationship between covariates and enrolment in the pre-ESRD P4P programme is unclear. Therefore, this study aimed to investigate factors associated with patient enrolment in the pre-ESRD P4P programme in Taiwan.

\section{MATERIAL AND METHODS Details of the P4P programme}

The Taiwan National Health Insurance Administration initiated the pre-ESRD P4P programme in November 2006. This is a patient care and education programme with health management of high-risk groups to improve healthcare and delay the onset of ESRD and dialysis. ${ }^{13}$ The patient inclusion criteria were as follows: patients with CKD stages 3b, 4 and 5 who had estimated glomerular filtration rates (eGFRs) of 30-44.9, 15-29.9 and $<15 \mathrm{~mL} /$ $\min / 1.73 \mathrm{~m}^{2}$, respectively; and patients with proteinuria, defined as daily urine protein $>1000 \mathrm{mg}$ or urine protein/ creatinine ratio $>1000 \mathrm{mg} / \mathrm{g}$. Multidisciplinary medical teams, including nephrologists, health education nurses and nutritionists, provided comprehensive medical assessment, laboratory examination and patient education every 3 months. Patients enrolled in the pre-ESRD $\mathrm{P} 4 \mathrm{P}$ programme were cared for according to applicable clinical guidelines at different stages of CKD.

Physicians reported the eGFR and urine albumin/ creatinine ratio (or urine protein/creatinine ratio) for every patient enrolled in the $\mathrm{P} 4 \mathrm{P}$ programme every 6 months. In addition, physicians also evaluated each enrolled patient annually, including management plans, medication, education programme and laboratory data. Cases were to be closed when renal function deteriorated and the patient received dialysis treatment, renal transplantation or hospice care, was transferred to other hospitals or died.

The health institute and multidisciplinary medical teams gained financial incentives if they achieved specific healthcare quality indicators. ${ }^{14}$ The incentives amount to US $\$ 40$, and the incentives for follow-up every 3 months equaled US $\$ 20$. Doctors are given incentives of US\$50 for cases for whom the decline of eGFR is less than $6 \mathrm{~mL} /$ $\min / 1.73 \mathrm{~m}^{2} /$ year among diabetic patients in CKD stages $3 \mathrm{~b}$ and 4 or less than $4 \mathrm{~mL} / \mathrm{min} / 1.73 \mathrm{~m}^{2} /$ year among non-diabetic patients in CKD stages $3 \mathrm{~b}$ and 4 . Doctors are given incentives of US $\$ 100$ for cases for whom the decline of eGFR is less than $6 \mathrm{~mL} / \mathrm{min} / 1.73 \mathrm{~m}^{2} /$ year among diabetic patients in CKD stage 5 or less than $4 \mathrm{~mL} /$ $\min / 1.73 \mathrm{~m}^{2} /$ year among non-diabetic patients in CKD stage 5. Doctors are paid incentives of US $\$ 35$ if a patient in ESRD prepares their fistula or catheter well before dialysis. If patients receive a living kidney transplant from a relative, the reward for doctors is US\$167.

\section{Data source}

We used the National Health Insurance research database 2007-2012 in Taiwan, which includes inpatient and outpatient medical care information. The National Health Insurance covered nearly $99 \%$ of the Taiwanese population. Disease diagnosis, treatment procedure, drugs and health expenditure were all included in the data set. ${ }^{15}$ The data used in the study were de-identified before analysis took place.

\section{Study population}

From 01 January 2007 to 31 December 2012, patients with diagnosis codes of chronic renal failure (International Classification of Diseases, Ninth Revision, Clinical Modification (ICD-9-CM) codes 585.xx or 581.9x) at least two times within 1 year were identified. ${ }^{16}$ The diagnosis codes of chronic renal failure (ICD-9-CM codes 585.xx or $581.9 x$ ) were coded by a nephrologist on a creatinine or proteinuria measurement. Then, those who were younger than 18 years, who had any dialysis records and who did not possess registries for beneficiaries were excluded. The final analytical sample comprised of 182087 participants.

\section{Outcome variable}

Those with procedure code of medical care in pre-ESRD $\mathrm{P} 4 \mathrm{P}$ programme (P3402C, P3403C and P3404C) were recognised as enrolled in the pre-ESRD $\mathrm{P} 4 \mathrm{P}$ programme. ${ }^{13}$

\section{Confounding variables}

Potential confounders included sex, age $(\leq 45,46-55$, 56-65, 66-75 and $\geq 76$ years), socioeconomic status (dependents and employed), residential urbanity (urban and rural), Charlson Comorbidity Index (CCI), index year, accreditation level (medical centre, regional hospital, district hospital and clinic), total pre-ESRD case volume $(<1300,1300-3000$ and $>3000)$, total P4P case volume $(<700,700-1500$ and $>1500)$, P4P pre-ESRD case volume $(<33 \%, 33 \%-67 \%$ and $>67 \%)$ and the hospitals' geographic locations (Taipei, northern, central, southern, Kao-Ping and eastern branches). Those people without income were defined as dependent. To investigate the role of urbanisation, all 365 townships of Taiwan were stratified into two levels, urban and rural. ${ }^{17}$ The level of medical institutions in Taiwan is divided into medical centres, regional hospitals, district hospitals and clinics 
according to the guidelines of the Ministry of Health and Welfare.

Comorbidities were identified from the National Health Insurance records with the definition of two or more ambulatory care claims or one inpatient claim. The following comorbidities were identified: diabetes mellitus (ICD-9-CM: 250), hypertension (ICD-9-CM: 401-405), myocardial infarction (ICD-9-CM: 410), congestive heart failure (ICD-9-CM: 428), stroke (ICD-9-CM: 433, 434 and 436), gout (ICD-9-CM: 274) and peripheral vascular disease (ICD-9-CM: 250.7, 443.00, 443.81, 443.9, 444.2 and 785.4$){ }^{18}$

\section{Statistical analyses}

Baseline characteristics of the participants in the $\mathrm{P} 4 \mathrm{P}$ and non-P4P groups were compared by two-sample t-test or $\chi^{2}$ test in continuous and categorical variables. Logistic regression models were employed with the generalised estimating equation (GEE) methods to investigate the factors associated with enrolment in the pre-ESRD P4P programme. ${ }^{19}$ A univariable analysis was performed initially to investigate factors associated with enrolment of pre-ESRD programme. Then, a multivariable analysis adjusted by patient demographics, comorbidities and healthcare institution characteristics was conducted. We performed two multivariable models, the first of which analysed each comorbidity and the second analysed the CCI. ORs were estimated from the GEE logistic regression model. We conducted all analyses using SAS statistical software package (V.9.3).

\section{Patient and public involvement}

Patients or the public were not involved in this study. They will be informed of the study results through publications.

\section{RESULTS}

Table 1 presents the baseline demographics of the study population. In total, 182087 patients with CKD were identified between 01 January 2007 and 31 December 2012. Among them, the mean (SD) age is 67.16 (14.51) years, and $107638(59.11 \%)$ were males. There were 82991 $(45.58 \%)$ and $99096(54.42 \%)$ in the pre-ESRD P4P and non-P4P groups, respectively. Patients who were females, of greater age, socioeconomically dependent, from rural residential areas and with comorbidities had higher participation rates. The total participation rate increased year by year. Regarding hospital characteristics, clinics, high case volumes and hospitals located in the central branch had higher participation rates.

Table 2 presents the result of the GEE logistic regression model. Model 1 is the univariate analysis of factors, namely, female patient (male, $\mathrm{OR}=0.91,95 \% \mathrm{CI}=0.88$ to $0.94)$, greater age $(76+$ years old, $\mathrm{OR}=1.37,95 \% \mathrm{CI}=1.24$ to 1.51) and socioeconomic dependence (employed, $\mathrm{OR}=0.88,95 \% \mathrm{CI}=0.86$ to 0.91 ), and those with diabetes mellitus $(\mathrm{OR}=1.62,95 \% \mathrm{CI}=1.55$ to 1.70$)$, hypertension
$(\mathrm{OR}=1.90,95 \% \mathrm{CI}=1.79$ to 2.01$)$, gout $(\mathrm{OR}=1.24,95 \%$ $\mathrm{CI}=1.19$ to 1.29$)$, peripheral vascular disease $(\mathrm{OR}=1.28$, $95 \% \mathrm{CI}=1.20$ to 1.36 ) or more comorbidities (CCI 5+, $\mathrm{OR}=5.50,95 \% \mathrm{CI}=4.62$ to 6.54$)$ were more likely to be enrolled in the pre-ESRD P4P programme. In hospital characteristics, no statistically significant result was noted. Models 2 and 3 were the multivariate analyses. The result showed that patients who were females (male, adjusted OR $(\mathrm{AOR})=0.89,95 \% \mathrm{CI}=0.86$ to 0.91 ), of greater age except for $76+$ years old (66-75 years old, AOR $=1.23$, $95 \% \mathrm{CI}=1.14$ to 133$)$ and socioeconomically dependent (employed, AOR $=0.95,95 \% \mathrm{CI}=0.92$ to 0.97 ) with higher comorbidities (CCI 5+, AOR=4.01, 95\% CI=3.55 to 4.53) were more likely to be enrolled in the programme. Patients who were older than 76 years did not have significantly increased odds of being enrolled in the P4P programme (AOR $=1.03,95 \% \mathrm{CI}=0.95$ to 1.13$)$. Hospitals located in the central $(\mathrm{AOR}=1.48,95 \% \mathrm{CI}=1.05$ to 2.08) and Kao-Ping regions (AOR $=1.62,95 \% \mathrm{CI}=1.18$ to 2.22) also tended to enrol patients in the pre-ESRD P4P programme.

\section{DISCUSSION}

Our study demonstrated that patients with greater age except for $76+$ years old, of the female gender, socioeconomic dependence and with diabetes, hypertension, gouty arthritis and peripheral vascular disease were more likely to be included in the pre-ESRD P4P programme. Hospitals located in the central and Kao-Ping regions also tended to enrol patients in the pre-ESRD P4P programme.

It was reported that diabetic patients with greater age and more comorbidities tended to be excluded from diabetes mellitus P4P programmes in Taiwan. ${ }^{20}$ Another study also indicated that patients with greater diabetes complication severity index and CCI tended to be excluded from the diabetes mellitus $\mathrm{P} 4 \mathrm{P}$ programme. ${ }^{21}$ In addition, patients of the male gender, younger than 35 years, living in urban areas, with greater diabetes complication severity index and commodity were more likely to interrupt the diabetes mellitus $\mathrm{P} 4 \mathrm{P}$ programme. ${ }^{22}$ According to the design of diabetes mellitus $\mathrm{P} 4 \mathrm{P}$ programme, physicians reported better haemoglobin A1c (HbA1c) and low-density lipoprotein (LDL) levels among participants and wound up reaping the reward for higher performance even if the care quality of all of their diabetic patients was not improved. Physicians may tend to choose healthier patients to join the diabetes mellitus $\mathrm{P} 4 \mathrm{P}$ programme. ${ }^{23}$ In contrast, the pre-ESRD P4P programme rewards physicians according to several domains, including patient health status (blood pressure, LDL, triglyceride, HbA1c and haemoglobin levels), patient participation in nutrition and nursing education programmes, and the proportion of well-prepared fistula. Health institutes would not potentially exclude patients of greater age or with more comorbidities to gain higher payments.

Management of the pre-ESRD $\mathrm{P} 4 \mathrm{P}$ programme in Taiwan is straightforward. The incentives of new patient 


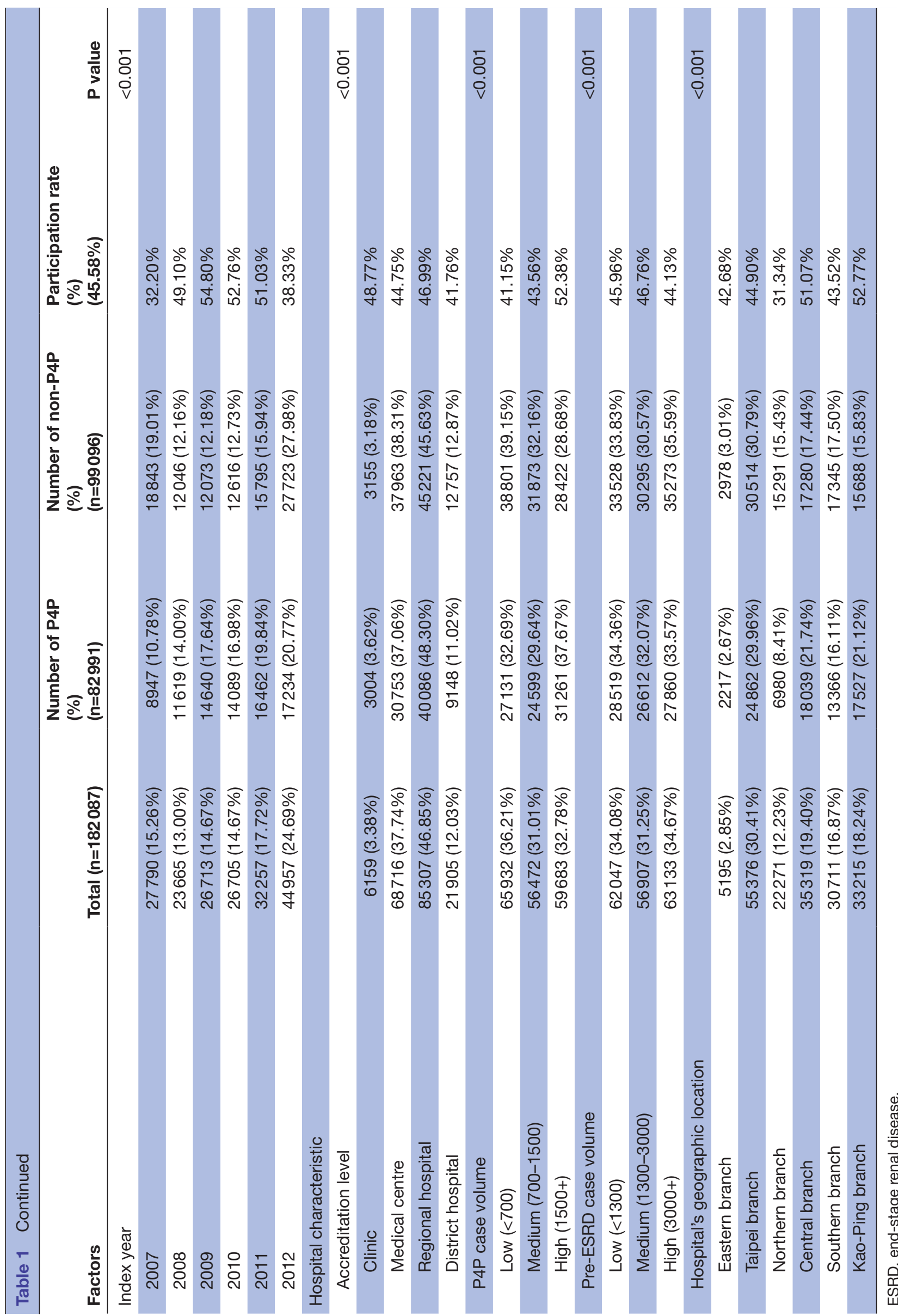


Table 2 Factors associated with enrolment in the pre-ESRD pay-for-performance programme by generalised estimating equation logistic regression model

\begin{tabular}{|c|c|c|c|c|c|c|}
\hline & Model 1 & & Model 2 & & Model 3 & \\
\hline Factors & OR & $95 \% \mathrm{Cl}$ & Adjusted OR & $95 \% \mathrm{Cl}$ & Adjusted OR & $95 \% \mathrm{Cl}$ \\
\hline \multicolumn{7}{|l|}{ Patient demographics } \\
\hline \multicolumn{7}{|l|}{ Sex } \\
\hline Female & Ref & & Ref & & Ref & \\
\hline Male & 0.91 & 0.88 to 0.94 & 0.89 & 0.86 to 0.91 & 0.89 & 0.86 to 0.91 \\
\hline \multicolumn{7}{|l|}{ Age, years } \\
\hline$\leq 45$ & Ref & & Ref & & Ref & \\
\hline $46-55$ & 1.38 & 1.30 to 1.46 & 1.17 & 1.12 to 1.23 & 1.18 & 1.13 to 1.24 \\
\hline $56-65$ & 1.57 & 1.47 to 1.69 & 1.22 & 1.15 to 1.30 & 1.25 & 1.17 to 1.33 \\
\hline $66-75$ & 1.66 & 1.52 to 1.80 & 1.23 & 1.15 to 1.32 & 1.23 & 1.14 to 1.33 \\
\hline $76+$ & 1.37 & 1.24 to 1.51 & 1.08 & 1.00 to 1.17 & 1.03 & 0.95 to 1.13 \\
\hline \multicolumn{7}{|l|}{ Socioeconomic status } \\
\hline Dependents & Ref & & Ref & & Ref & \\
\hline Employed & 0.88 & 0.86 to 0.91 & 0.95 & 0.92 to 0.98 & 0.95 & 0.92 to 0.97 \\
\hline \multicolumn{7}{|l|}{ Residential urbanity } \\
\hline Rural & Ref & & Ref & & Ref & \\
\hline Urban & 1.01 & 0.98 to 1.04 & 0.99 & 0.93 to 1.05 & 1 & 0.94 to 1.06 \\
\hline \multicolumn{7}{|l|}{ Comorbidities } \\
\hline Diabetes mellitus & 1.62 & 1.55 to 1.70 & 1.48 & 1.43 to 1.54 & & \\
\hline Hypertension & 1.9 & 1.79 to 2.01 & 1.6 & 1.54 to 1.66 & & \\
\hline Myocardial infarction & 1.06 & 0.96 to 1.16 & 0.9 & 0.83 to 0.98 & & \\
\hline Congestive heart failure & 1.08 & 1.02 to 1.15 & 0.97 & 0.93 to 1.01 & & \\
\hline Stroke & 1.06 & 1.01 to 1.11 & 0.95 & 0.91 to 0.99 & & \\
\hline Gout & 1.24 & 1.19 to 1.29 & 1.21 & 1.17 to 1.26 & & \\
\hline Peripheral vascular disease & 1.28 & 1.20 to 1.36 & 1.07 & 1.01 to 1.13 & & \\
\hline \multicolumn{7}{|l|}{ Charlson Comorbidity Index } \\
\hline 0 & Ref & & & & Ref & \\
\hline $1-2$ & 3.07 & 2.71 to 3.48 & & & 2.38 & 2.19 to 2.59 \\
\hline $3-4$ & 4.49 & 3.85 to 5.23 & & & 3.32 & 3.00 to 3.68 \\
\hline $5+$ & 5.5 & 4.62 to 6.54 & & & 4.01 & 3.55 to 4.53 \\
\hline \multicolumn{7}{|l|}{ Index year } \\
\hline 2007 & Ref & & Ref & & Ref & \\
\hline 2008 & 1.89 & 1.51 to 2.37 & 2.36 & 1.85 to 3.01 & 2.37 & 1.86 to 3.02 \\
\hline 2009 & 2.33 & 1.84 to 2.97 & 3.29 & 2.52 to 4.29 & 3.28 & 2.52 to 4.27 \\
\hline 2010 & 2.18 & 1.70 to 2.80 & 3.09 & 2.33 to 4.09 & 3.09 & 2.33 to 4.09 \\
\hline 2011 & 2.05 & 1.60 to 2.62 & 2.7 & 2.05 to 3.54 & 2.74 & 2.09 to 3.59 \\
\hline 2012 & 1.23 & 0.96 to 1.57 & 1.6 & 1.23 to 2.10 & 1.64 & 1.26 to 2.15 \\
\hline \multicolumn{7}{|l|}{ Hospital characteristic } \\
\hline \multicolumn{7}{|l|}{ Accreditation level } \\
\hline Clinic & Ref & & Ref & & Ref & \\
\hline Medical centre & 0.95 & 0.69 to 1.31 & 0.86 & 0.38 to 1.94 & 0.81 & 0.35 to 1.83 \\
\hline Regional hospital & 0.9 & 0.66 to 1.22 & 0.9 & 0.43 to 1.91 & 0.84 & 0.40 to 1.78 \\
\hline District hospital & 0.75 & 0.54 to 1.03 & 0.74 & 0.35 to 1.58 & 0.7 & 0.32 to 1.49 \\
\hline Pre-ESRD case volume & & & & & & \\
\hline
\end{tabular}


Table 2 Continued

\begin{tabular}{|c|c|c|c|c|c|c|}
\hline \multirow[b]{2}{*}{ Factors } & \multicolumn{2}{|c|}{ Model 1} & \multicolumn{2}{|l|}{ Model 2} & \multicolumn{2}{|l|}{ Model 3} \\
\hline & OR & $95 \% \mathrm{Cl}$ & Adjusted OR & $95 \% \mathrm{Cl}$ & Adjusted OR & $95 \% \mathrm{Cl}$ \\
\hline Low $(<1300)$ & Ref & & Ref & & Ref & \\
\hline Medium (1300-3000) & 1.13 & 0.88 to 1.45 & 0.92 & 0.67 to 1.27 & 0.92 & 0.67 to 1.26 \\
\hline High (3000+) & 1.06 & 0.77 to 1.47 & 0.92 & 0.56 to 1.50 & 0.9 & 0.55 to 1.46 \\
\hline \multicolumn{7}{|c|}{ Hospital's geographic location } \\
\hline Eastern branch & Ref & & Ref & & Ref & \\
\hline Taipei branch & 1 & 0.69 to 1.45 & 1.14 & 0.82 to 1.60 & 1.19 & 0.84 to 1.68 \\
\hline Northern branch & 1.28 & 0.96 to 1.69 & 0.63 & 0.29 to 1.34 & 0.64 & 0.30 to 1.38 \\
\hline Central branch & 0.96 & 0.66 to 1.40 & 1.45 & 1.03 to 2.03 & 1.48 & 1.05 to 2.08 \\
\hline Southern branch & 1.13 & 0.82 to 1.54 & 1.07 & 0.73 to 1.57 & 1.1 & 0.75 to 1.62 \\
\hline Kao-Ping branch & 0.71 & 0.46 to 1.11 & 1.58 & 1.16 to 2.15 & 1.62 & 1.18 to 2.22 \\
\hline
\end{tabular}

Model 1 is the univariate analysis.

Model 2 is the multivariate analysis with patient and hospital characteristics, and specific diseases adjusted.

Model 3 is the multivariate analysis with patient and hospital characteristics, and Charlson Comorbidity Index adjusted.

ESRD, end-stage renal disease; Ref, reference.

enrolment are US $\$ 40$, and the incentives for follow-up every 3 months are US\$20. The total incentives for each patient are US $\$ 100$ per year for the hospital. The performance was measured by the decline of eGFR, remission of proteinuria, fistula preparation and renal transplantation. There were no penalties for poor performance or the effect on outcome in the pre-ESRD P4P programme. Doctors would not be more likely to enrol healthier patients to gain more incentives. This could be the reason that patients with greater age, of the female gender, socioeconomic dependence and more comorbidities were more likely to be included in the pre-ESRD P4P programme.

Many countries have different health insurance systems and various disease management programmes. Previous studies have demonstrated that patients under healthcare from the $\mathrm{P} 4 \mathrm{P}$ programme will receive guideline-recommended tests and examinations. ${ }^{24}$ A meta-analysis by Mendelson et al analysed 69 studies and reported that $\mathrm{P} 4 \mathrm{P}$ programme may be related to improving the care process in an outpatient setting, but a positive association with improved health outcomes was not demonstrated. ${ }^{25}$ The Taiwan National Health Insurance Administration, Ministry of Health and Welfare had implemented the early CKD P4P programme, which enrolled patients with CKD stages 1-3a; and the pre-ESRD P4P programme, which enrolled patients with CKD stages $3 b-5$. In recent years, many domestic research papers on CKD and pre-ESRD P4P programme have shown that patients under $\mathrm{P} 4 \mathrm{P}$ care programme can delay the progression of CKD to the ESRD ${ }^{26}$ reduce CKD mortality and hospitalisation rate, ${ }^{27}$ and slow renal function deterioration rate. ${ }^{28}$ Patients also have better medical care and quality of life and reduced medical expenses..$^{29}$ The CKD and pre-ESRD P4P programmes were confirmed as successful programmes. Another study confirmed that patients with advanced stages of CKD had higher rates of established arteriovenous access before entering haemodialysis if they were under integrated $\mathrm{P} 4 \mathrm{P}$ care programme,${ }^{31}$ thus avoiding hospitalisation during dialysis, which can reduce hospitalisation costs and overall medical expenses. ${ }^{31}$ The patient who implemented the fistula before dialysis had a significantly lower length of hospital stay and hospitalisation costs, compared with those with no well-prepared fistula. ${ }^{32}$ It was also reported that early CKD patients had lower annual eGFR deterioration rate if they were under the care of a nephrologist. ${ }^{33}$

This study had several strengths. We used the nationwide health insurance data which is representative for the whole Taiwan population. Both patient and provider factors were analysed, and a GEE was used to verify the results. Detailed patients and hospital characteristics were compared and analysed.

This study also had some limitations that should be mentioned. This was a cross-sectional study, in which it is difficult to investigate causal relationships. There were some uncontrolled variables. Laboratory data were not available in the health insurance data set. Patient characteristics, including education level, marriage, income, smoking and drinking habits, and medical adherence, were not included in the analysis. Physician characteristics, such as age, sex, education levels, specialisation, annual salary and the volume of serviced patients, were not available. The reward and total payment gained by health institutes and physicians from the P4P programme were not analysed. The national health insurance system and the pre-ESRD $\mathrm{P} 4 \mathrm{P}$ programme are unique in Taiwan, and the results may not apply to other countries in the world.

CKD is a complex and multicause disease. A new concept for an integrated care plan for patients with CKD is necessary. The result of the current study indicated that those who were male, younger, socioeconomically 
independent and had less comorbidities were overlooked by the pre-ESRD P4P programme. The National Health Insurance system of Taiwan covers nearly $99 \%$ of the Taiwanese population and also supports the unique pre-ESRD P4P reimbursement system. This may be the reason that those who were greater age, with socioeconomic dependence and more comorbidities were tended to receive $\mathrm{P} 4 \mathrm{P}$ enrolment.

\section{CONCLUSIONS}

In summary, patients of the female gender, greater age except for $76+$ years old, with socioeconomic dependence and more comorbidities were likely to be enrolled in the pre-ESRD $\mathrm{P} 4 \mathrm{P}$ programme and received multidisciplinary care. In the future, policymakers must consider approaches for improving the participation rate in the pre-ESRD P4P programme to achieve better healthcare quality and disease outcome.

\section{Author affiliations}

${ }^{1}$ Institute of Public Health, National Yang-Ming University, Taipei, Taiwan

${ }^{2}$ Faculty of Renal Care, College of Medicine, Kaohsiung Medical University,

Kaohsiung, Taiwan

${ }^{3}$ Division of Endocrinology and Metabolism, Department of Internal Medicine, Puli

Branch of Taichung Veterans General Hospital, Nantou, Taiwan

${ }^{4}$ Section of Infectious Diseases, Taipei City Hospital, Taipei, Taiwan

${ }^{5}$ Institute of Hospital and Health Care Administration, National Yang-Ming University,

Taipei, Taiwan

${ }^{6}$ Division of Nephrology, Department of Internal Medicine, Kaohsiung Medical University Hospital, Kaohsiung, Taiwan

Contributors $\mathrm{H}-\mathrm{YH}$ and $\mathrm{Y}-\mathrm{jL}$ contributed to study design and conceptual framework. SJH and Y-FY obtained the data and participated in the statistical analysis. NH, F-XJ and Y-FY wrote the initial depiction of the manuscript. All the authors revised the article and gave final approval.

Funding This study was supported by the Taiwan Ministry of Education through its 'Aim for the Top University Plan', and by grants from the National Health Insurance Administration, Ministry of Health and Welfare (MOHW103-NH-1001 and MOHW107-NHI-S-114-000001). This study was funded by the Ministry of Science and Technology, Taiwan (MOST103-2410-H-028-001-MY2), and the Taipei City Hospital, Taiwan (TPCH-108-05).

Competing interests None declared.

Patient consent for publication Not required.

Provenance and peer review Not commissioned; externally peer reviewed. Data availability statement № data are available.

Open access This is an open access article distributed in accordance with the Creative Commons Attribution Non Commercial (CC BY-NC 4.0) license, which permits others to distribute, remix, adapt, build upon this work non-commercially, and license their derivative works on different terms, provided the original work is properly cited, appropriate credit is given, any changes made indicated, and the use is non-commercial. See: http://creativecommons.org/licenses/by-nc/4.0/.

\section{REFERENCES}

1. Gansevoort RT, Correa-Rotter R, Hemmelgarn BR, et al. Chronic kidney disease and cardiovascular risk: epidemiology, mechanisms, and prevention. Lancet 2013;382:339-52.

2. Hill NR, Fatoba ST, Oke JL, et al. Global prevalence of chronic kidney disease - a systematic review and meta-analysis. PLoS One 2016:11:e0158765.

3. Prasad N, Jha V. Hemodialysis in Asia. Kidney Dis 2015;1:165-77.
4. Hsieh H-M, Lin M-Y, Chiu Y-W, et al. Economic evaluation of a preESRD pay-for-performance programme in advanced chronic kidney disease patients. Nephrol Dial Transplant 2017;32:1184-94.

5. Hemmelgarn BR, Manns BJ, Zhang J, et al. Association between multidisciplinary care and survival for elderly patients with chronic kidney disease. J Am Soc Nephro 2007;18:993-9.

6. Desai AA, Garber AM, Chertow GM. Rise of pay for performance: implications for care of people with chronic kidney disease. Clin J Am Soc Nephro 2007;2:1087-95.

7. Howard K, White S, Salkeld G, et al. Cost-Effectiveness of screening and optimal management for diabetes, hypertension, and chronic kidney disease: a modeled analysis. Value Health 2010;13:196-208.

8. Karunaratne K, Stevens P, Irving J, et al. The impact of pay for performance on the control of blood pressure in people with chronic kidney disease stage 3-5. Nephrol Dial Transplant 2013;28:2107-16.

9. Kondo M, Yamagata K, Hoshi S-L, et al. Cost-effectiveness of chronic kidney disease mass screening test in Japan. Clin Exp Nephrol 2012;16:279-91.

10. Lin M-Y, Cheng L-J, Chiu Y-W, et al. Effect of national pre-ESRD care program on expenditures and mortality in incident dialysis patients: a population-based study. PLOS One 2018;13:e0198387.

11. Nephrology Tso. TW ESRD registry, 2017. Available: https://www.tsn. org.tw/UI/L/L002.aspx

12. Fishbane $S$, Hazzan $A D$, Halinski $C$, et al. Challenges and opportunities in late-stage chronic kidney disease. Clin Kidney $\mathrm{J}$ 2015;8:54-60.

13. Lin C-M, Yang M-C, Hwang S-J, et al. Progression of stages 3b-5 chronic kidney disease - preliminary results of Taiwan national preESRD disease management program in Southern Taiwan. $J$ Formos Med Assoc 2013;112:773-82.

14. National health insurance administration, Ministry of health and welfare, Taiwan: Pre-ESRD patient care and education program in Taiwan. Available: https://www.nhi.gov.tw/Content_List.aspx? $\mathrm{n}=$ D037A6FEDF678C70\&topn=D39E2B72B0BDFA15 [Accessed 29 Jan 2019].

15. Hsing AW, loannidis JPA. Nationwide population science: lessons from the Taiwan National health insurance research database. JAMA Intern Med 2015;175:1527-9.

16. Shih C-J, Chen Y-T, Ou S-M, et al. The impact of dialysis therapy on older patients with advanced chronic kidney disease: a nationwide population-based study. BMC Med 2014;12:169.

17. Liu C-Y, Hung Y-T, Chuang Y-L, et al. Incorporating development stratification of Taiwan Townships into sampling design of large scale health interview survey. $J$ Health Manag 2006;4:1-22.

18. Lai $\mathrm{Y}-\mathrm{J}, \mathrm{Hu} \mathrm{H}-\mathrm{Y}$, Lin $\mathrm{C}-\mathrm{H}$, et al. Incidence and risk factors of lower extremity amputations in people with type 2 diabetes in Taiwan, 2001-2010. J Diabetes 2015;7:260-7.

19. Aitkin M. A general maximum likelihood analysis of variance components in generalized linear models. Biometrics 1999;55:117-28.

20. Chen T-T, Chung K-P, Lin I-C, et al. The unintended consequence of diabetes mellitus pay-for-performance (P4P) program in Taiwan: are patients with more comorbidities or more severe conditions likely to be excluded from the P4P program? Health Serv Res 2011;46:47-60.

21. Hsieh H-M, Tsai S-L, Mau L-W, et al. Effects of changes in diabetes pay-for-performance incentive designs on patient risk selection. Health Serv Res 2016;51:667-86.

22. Yen S-M, Kung P-T, Sheen Y-J, et al. Factors related to continuing care and interruption of P4P program participation in patients with diabetes. Am J Manag Care 2016;22:e18-30.

23. Chang R-E, Lin S-P, Aron DC. A pay-for-performance program in Taiwan improved care for some diabetes patients, but doctors may have excluded sicker ones. Health Aff 2012;31:93-102.

24. Lai C-L, Hou Y-H. The association of clinical guideline adherence and pay-for-performance among patients with diabetes. J Chin Med Assoc 2013;76:102-7.

25. Mendelson A, Kondo K, Damberg C, et al. The effects of pay-forperformance programs on health, health care use, and processes of care: a systematic review. Ann Intern Med 2017;166:341-53.

26. Chen PM, Lai TS, Chen PY, et al. Multidisciplinary care program for advanced chronic kidney disease: reduces renal replacement and medical costs. Am J Med 2015;128:68-76.

27. Wu I-W, Wang S-Y, Hsu K-H, et al. Multidisciplinary predialysis education decreases the incidence of dialysis and reduces mortality-a controlled cohort study based on the NKF/DOQI guidelines. Nephrol Dial Transplant 2009;24:3426-33.

28. Chen Y-R, Yang Y, Wang S-C, et al. Effectiveness of multidisciplinary care for chronic kidney disease in Taiwan: a 3-year prospective cohort study. Nephrol Dial Transplant 2013;28:671-82. 
29. Chen Y-R, Yang Y, Wang S-C, et al. Multidisciplinary care improves clinical outcome and reduces medical costs for pre-end-stage renal disease in Taiwan. Nephrology 2014;19:699-707.

30. Yu Y-J, Wu I-W, Huang C-Y, et al. Multidisciplinary predialysis education reduced the inpatient and total medical costs of the first 6 months of dialysis in incident hemodialysis patients. PLoS One 2014;9:e112820

31. Wei S-Y, Chang Y-Y, Mau L-W, et al. Chronic kidney disease care program improves quality of pre-end-stage renal disease care and reduces medical costs. Nephrology 2010;15:108-15.
32. Wu L-C, Lin M-Y, Hsieh C-C, et al. Planned creation of vascular access saves medical expenses for incident dialysis patients. Kaohsiung J Med Sci 2009;25:521-9.

33. Chen S-C, Chang J-M, Chou M-C, et al. Slowing renal function decline in chronic kidney disease patients after nephrology referral. Nephrology 2008;13:730-6. 